\title{
Heinz Schilling, 1517. Weltgeschichte eines Jahres
}

\section{Gérald Chaix}

\section{OpenEdition \\ Journals}

Édition électronique

URL : http://journals.openedition.org/ifha/9268

DOI : $10.4000 /$ ifha. 9268

ISSN : 2198-8943

Éditeur

IFRA - Institut franco-allemand (sciences historiques et sociales)

\section{Référence électronique}

Gérald Chaix, "Heinz Schilling, 1517. Weltgeschichte eines Jahres », Revue de l'IFHA [En ligne], Date de recension, mis en ligne le 20 juin 2018, consulté le 24 septembre 2020. URL : http:// journals.openedition.org/ifha/9268; DOI : https://doi.org/10.4000/ifha.9268

Ce document a été généré automatiquement le 24 septembre 2020.

(C)IFHA 


\title{
Heinz Schilling, 1517. Weltgeschichte eines Jahres
}

\author{
Gérald Chaix
}

\section{RÉFÉRENCE}

Heinz Schilling, 1517. Weltgeschichte eines Jahres, München: C.H. Beck, 2017, 364 p., $24,95 €$ 
Quatre témoignages empruntés à l'Italie, au Mexique, à la Chine et à la Saxe de Martin Luther servent de prologue et permettent à Heinz Schilling de brosser l'arrière-plan de son tableau. Celui d'un monde incertain, en pleine mutation, auquel Dieu donne sens. Un monde différent du nôtre, globalisé et sécularisé, par le rapport qu'il a au temps, à l'environnement, à la nourriture et à la santé corporelle. À l'orée du XVI ${ }^{\mathrm{e}}$ siècle, deux empires coexistent à l'échelle mondiale : celui des Habsbourg et celui des Ottomans, tandis qu'une "troisième Rome » se profile à Moscou. C'est un monde qui désire la paix et la stabilité de l'argent, condition des échanges, ainsi que le rappelle Copernic, précisément en 1517. C'est un monde dominé par une Europe qui part à sa conquête, comme en

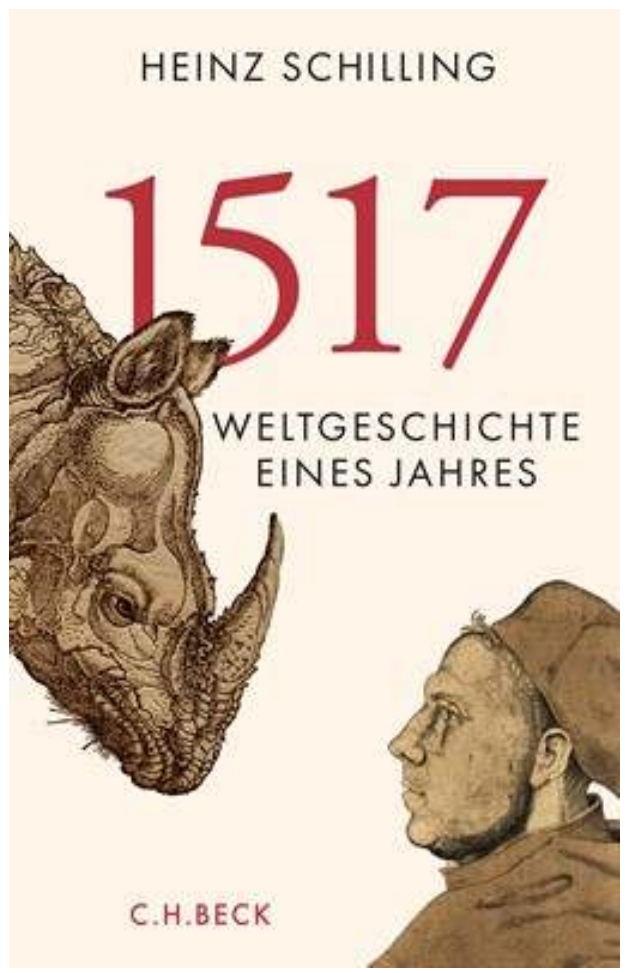
témoigne la rencontre des Espagnols, au Yucatan, avec la civilisation américaine.

C'est aussi, bien sûr, le temps de la Renaissance. Ce monde est en même temps celui du surnaturel, de la magie, de la sorcellerie et des démons. Dans la chrétienté latine, il a pour boucs émissaires les Juifs et les Musulmans, rencontrés pour ces derniers dans le cadre de l'expansion ottomane. Une chrétienté latine où s'affirme l'autorité du pape, en l'occurrence Léon X, défenseur des intérêts de sa famille, celle des Médicis, et principal acteur politique du moment sur la scène italienne et européenne. Il est en même temps porteur des attentes de Réforme, comme vient de le rappeler le cinquième concile réuni au Latran, qui trouve en Cisneros son porte-parole.

L'année 1517 est aussi celle de l'apparition sur la scène du frère augustin Martin Luder, professeur à l'université de Wittenberg. La publication des thèses d'octobre est pour lui une «libération». Mais leur diffusion assure à Luther une audience qui dépasse largement le monde universitaire. C'est leur résonance existentielle, très différente de l'ironie même acerbe d'Érasme (en 1517 justement paraît le Julius exclusus, rédigé durant le séjour londonien d'Érasme, en 1514, au lendemain de la mort du pape Jules II, ainsi exclu du paradis pour ses turpitudes), qui va susciter l'engouement. Ce n'est ni la critique des indulgences ni même celle de la papauté qui assurent le succès de leur auteur, mais la justification par la foi que Luther ne cesse dès lors d'affirmer et de préciser. Empruntant à Berndt Hamm le concept de Zentrierung, H. Schilling suggère que Luther fait la synthèse de deux réformes distinctes, l'une intellectuelle et scientifique, l'autre spirituelle et existentielle, et "recentre" la promesse du salut autour du Christ, de la foi et de la grâce et d'eux seuls. Il est alors possible d'inscrire l'action de Luther dans la continuité d'un monde dont la religion demeure le ciment (" religio vinculum societatis ») et de la penser cependant comme rupture. Cette fois à l'échelle même du monde, grâce au beau livre de H. Schilling. 
INDEX

Index chronologique : Période moderne

Thèmes : Histoire religieuse ; Histoire des mentalités

\section{AUTEURS}

\section{GÉRALD CHAIX}

Université de Tours, UMR 7323 